\title{
Updated status of Bayou darter, a narrowly ranged endemic in a geomorphically active watershed
}

\author{
Joshua Hubbell, Loren Stearman, Jacob Schaefer*
}

School of Biological, Environmental, and Earth Sciences, University of Southern Mississippi, Hattiesburg, Mississippi 39406, USA

\begin{abstract}
Comparison of historical and current data are critical in establishing population trends for imperiled taxa. In this paper we revisit the status of the Bayou darter Nothonotus rubrum, an endemic fish restricted to the Bayou Pierre river system, Mississippi, USA. The Bayou Pierre has experienced substantial geomorphic change in the past century, leading to questions about persistence of this imperiled species. We employed historical field notes and museum records to identify collection localities, and we resampled 32 of these localities using methodologies comparable to the original samples. We further sampled an additional 10 sites with similar methodologies to fill in spatial data gaps. Rates of capture and numbers of individuals were similar between historical and contemporary samples; however, collections with multiple individuals in contemporary samples were largely restricted to the upstream periphery of their historical distribution. Qualitative comparisons of numbers of individuals caught over several decades using variable methodology suggest that declines in abundances have happened since the species was first described. Bayou darter occupancy was positively related to stream link magnitude (beta estimate $=3.07$ ), and $\mathrm{N}$-mixture modeling estimated contemporary abundance at $7.36 \pm 3.83$ individuals per site. Bayou darter counts were negatively related to variance in kilometer-scale stream elevation (beta estimate $=-0.60$ ). Our results suggest that this species remains imperiled and is experiencing a declining range, and that continued efforts to study and monitor this species, and to reduce geomorphic change in the system, are merited.
\end{abstract}

KEY WORDS: Bayou Pierre $\cdot$ Erosion $\cdot$ Occupancy $\cdot$ Distribution $\cdot$ Assemblage change

\section{INTRODUCTION}

Conservation efforts for freshwater fishes are rapidly reaching a critical turning point at which sufficient long-term monitoring of some endangered but neglected species has begun to enable robust assessments of their present status compared to their past status. A limited minority of fishes are well studied due to their cultural or economic importance, and considerable inferences have been made about how their ranges or abundances have changed over time (e.g. black basses, Taylor et al. 2019; salmonids, Quinn 2018). But for most freshwater fishes, data deficiencies on populations, distributions, and even basic life histories have historically been the norm

${ }^{*}$ Corresponding author: jake.schaefer@usm.edu rather than the exception (Jelks et al. 2008, Matthews 2015). Detailed documentation of known species distributions, ecologies, and conservation statuses began to appear in the second half of the 20th century, and these works were heavily informed by regional surveys, status updates, museum specimens, and personal field notes (Cross 1967, Deacon et al. 1979, Williams et al. 1989, Etnier \& Starnes 1993, Ross 2000, Robison \& Buchanan 2020). The first few decades of the 21st century have seen researchers revisit these efforts and provide the beginnings of some quantitative estimates of changes to distributions and population statuses of neglected taxa (Jelks et al. 2008, Robison \& Buchanan 2020). Yet the ability to make such assessments is critically dependent on

(1) The authors 2021. Open Access under Creative Commons by Attribution Licence. Use, distribution and reproduction are unrestricted. Authors and original publication must be credited. 
continued collection of raw data sources, especially museum collections (Lister 2011) and status updates of individual endangered taxa conducted to be congruent with previous research efforts.

The Bayou darter Nothonotus rubrum was described in 1966 (Raney \& Suttkus 1966) and is endemic to the Bayou Pierre system in southwestern Mississippi (Suttkus \& Clemmer 1977). Given the small range and ongoing habitat degradation $(\mathrm{Ku}-$ hajda et al. 2009), it is currently listed as threatened under the US Endangered Species Act and endangered by the state of Mississippi. N. rubrum occupy a fairly specific habitat, specializing in shallow riffles or runs with large substrate and fast current velocities in Bayou Pierre proper and the lower reaches of some of the larger Bayou Pierre tributaries (see Fig. 1). Spawning occurs in April and May over gravel and coarse sand substrate (Ross \& Wilkins 1993, Slack et al. 2004). N. rubrum feed opportunistically on invertebrates found in faster-flowing habitats, with chironomids (midges), simuliids (blackflies), and Hydracarina (water mites) making up most of the stomach contents (Knight \& Ross 1994). Previous surveys for the species have identified a number of healthy populations, primarily in middle/upper Bayou Pierre, Foster Creek, Turkey Creek, and White Oak Creek (Ross et al. 1992). There have been a small number of new localities reported over the last 10-15 yr, including a new locality below the confluence of Bayou Pierre and Little Bayou Pierre, and another in Tallahalla Creek. In general, these are collections with few individuals and suggest the distribution remains unknown or is changing. While portions of the range have been surveyed, there has not been a survey across the distribution of this species in nearly 30 years.

Given the close proximity and similar habitats, one might think $N$. rubrum could also occur in Little Bayou Pierre (see Fig. 1). Both Ross et al. (1990) and Slack et al. (2004) noted the lack of N. rubrum in what appeared to be suitable habitat in Little Bayou Pierre. Given the life history and potential for colonizing previously unoccupied areas, a more thorough survey of Little Bayou Pierre was conducted in 2010. That work documented similar habitat structure, but fish assemblages in Little Bayou Pierre were more distinct than expected, and there were no occurrences of $N$. rubrum. While the assemblages differed, there were no other species found to be exclusive to one area or the other in that study (Schaefer 2011).

Conservation research efforts to date have focused on surveys, population estimates, population genetics, life history and microhabitat assessments (Knight
\& Ross 1992, Ross et al. 2001, Slack et al. 2010). Population genetic work on the 4 most robust populations (Foster Creek, upper Bayou Pierre, middle Bayou Pierre below Turkey Creek confluence, and Bayou Pierre near White Oak Creek confluence) found very little genetic structure or diversity, indicators of small population sizes and recent bottlenecks (Slack et al. 2010). The major threats to the species are erosion (directly removing viable habitat) resulting from extensive headcutting in the system coupled with the extremely limited range. Various activities in the Bayou Pierre system and downstream Mississippi River have dramatically altered the physical structure of the system (Slack et al. 2004, 2010). Substrate instability and rapid changes to river geomorphology have resulted in changes in fish assemblages, particularly for darters that have close ties to the benthos (Tipton et al. 2004). Conservation recommendations for Bayou Pierre include restricting gravel mining and other activities that accelerate headcutting and destabilize banks in the system (Kuhajda et al. 2009). There are some indications that populations have moved in response to erosion-facilitated habitat modifications. However, populations below assumed current active headcutting regions appear small, and have not been systematically sampled. Slack et al. (2004) hypothesized that larvae may drift downstream and later migrate upstream, indicating the species has the potential for colonizing favorable habitat in other tributaries. This would also result in populations being isolated around falls associated with migrating knickpoints. While Slack et al. (2004) could not definitively support this hypothesis, larvae are known to drift, and short-term colonization upstream is probable. The mobility of this species might also explain a changing distribution and new, and possibly sporadic, localities reported throughout the system.

The goals of the present project are to (1) survey historical localities of $N$. rubrum throughout the species' range to assess assemblage changes and verify if $N$. rubrum populations still persist at localities where they were previously documented, (2) survey areas where there have been anecdotal $N$. rubrum records, or where there may be suitable habitat but no historical collections, and (3) use hierarchical models to evaluate multiple working hypotheses to better understand patterns in Bayou darter occupancy and abundance at multiple spatial extents. For contemporary surveys, we utilized similar methods employed in previous surveys to contextualize our results and better inform future management decisions regarding $N$. rubrum. 


\section{MATERIALS AND METHODS}

\subsection{Site selection}

We acknowledge that the history of ichthyological explorations in the Bayou Pierre includes a tremendous amount of research effort by multiple teams (Teels 1976, Matthews 1978, Ross et al. 1992, 2001, Slack et al. 2004). The differences in goals, spatial extent, sampling methods, and degree of data availability make comparisons across many of these datasets challenging and beyond the scope of our project. After thorough review of literature, museum records, and field notes, we selected a series of sites that had complete assemblage data (sampling all habitats without targeting any one) throughout the basin with documented effort and gear (detailed in Section 2.2) used during the relatively brief window in the late 1980s to early 1990s (Fig. 1, Table 1). The purpose of our study is not to review all historical sampling efforts, but to make direct comparisons of samples using known methods roughly 30 yr apart. We further supplemented these sites with a smaller number of sites spread throughout regions of the basin which have historically been undersampled. Sampling occurred throughout the watershed including upper portions indicated by Ross et al. (2001) to be undergoing active erosion, and lower portions where Slack et al. (2004) demonstrated continued Nothonotus rubrum presence.

We identified 32 localities which were sampled with known effort 1 to 4 times (1987-1992) within a $1 \mathrm{~km}$ radius of an available access point and which had associated fish community data collected with standardized effort (Fig. 1). We further randomly selected 10 sites spread among Little Tallahalla Creek, White Oak Creek, the headwaters of the Little Bayou Pierre, and the mainstem Bayou Pierre below the confluence of the Little Bayou Pierre to fill in gaps for areas that were not historically sampled. The fish assemblage data from 1987-1992 includes 51 samples collected from 32 sites (hereinafter called historical data), which was combined with our 42 samples (hereinafter called contemporary data, see below).

The sampled sites covered most of the known distribution (highlighted river sections in Fig. 1) and include populations cited as being the most robust (Slack et al. 2010). There are many additional histor-

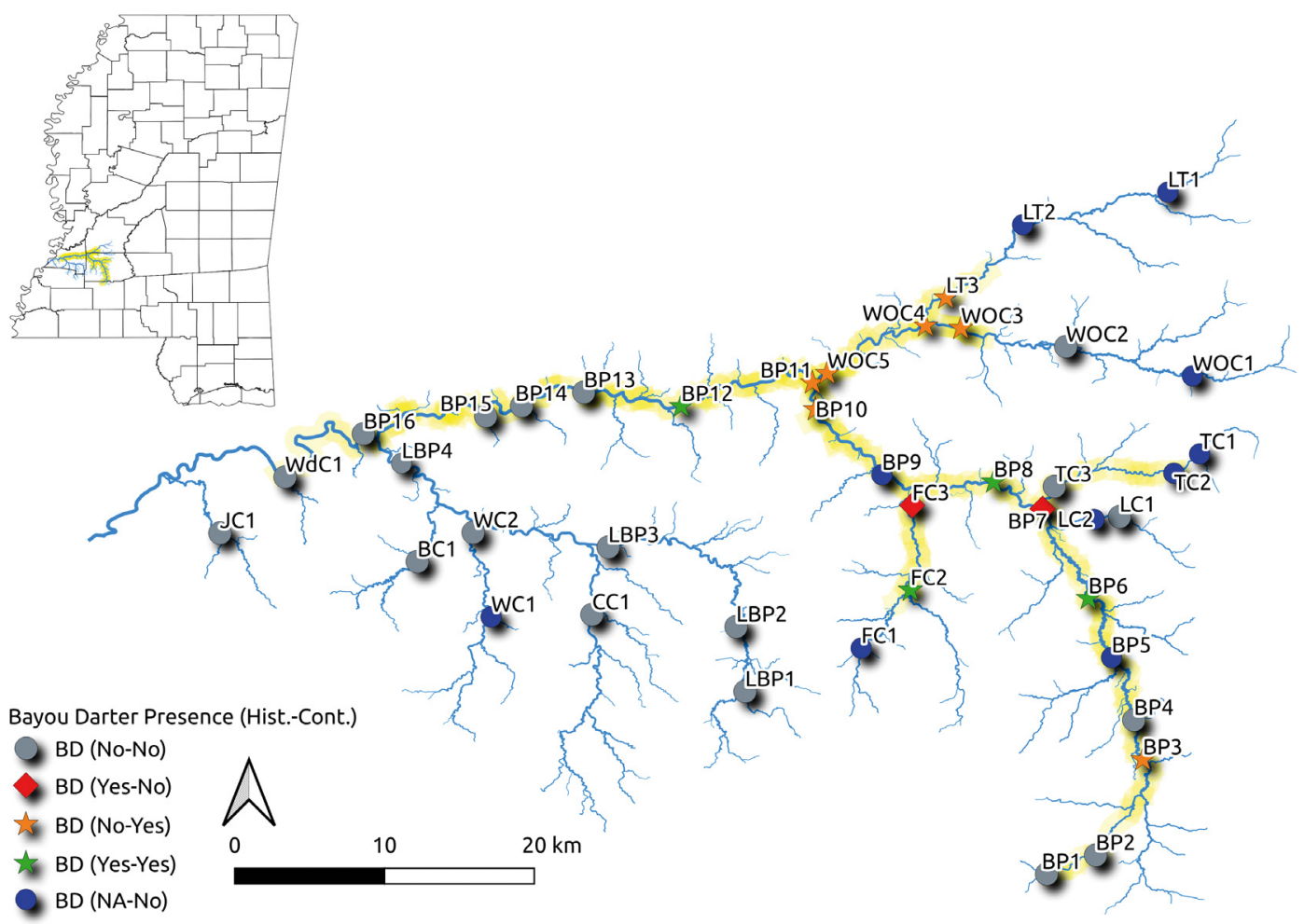

Fig. 1. All sampling locations from 2019 (see Table 1 for details of each site) within the Bayou Pierre system (inset: Mississippi, USA). Symbols represent the presence of assemblage data in the historical (Hist.) dataset (blue circles: no historical data available [NA]; all other symbols: historical data available) and the presence of Bayou darter (BD) Nothonotus rubrum in 2019 samples (Cont.: contemporary; stars: present; circles or diamonds: absent). Highlighted segments of river represent the entire known range of the species 
Table 1. The 42 sites sampled, locality, county, GPS coordinates, and the presence or absence of Bayou darter ('BD Pres') Nothonotus rubrum in 2019-2020 samples (and number collected) and in historical collections from the Bayou Pierre river system, MS, USA. Site labels match those in Fig. 1. HWY: highway: SHWY: state highway

\begin{tabular}{|c|c|c|c|c|c|c|c|}
\hline Site & Locality & County & Date (m/d/y) & $\begin{array}{l}\text { Latitude } \\
\left({ }^{\circ} \mathrm{N}\right)\end{array}$ & $\begin{array}{l}\text { Longitude } \\
\qquad\left({ }^{\circ} \mathrm{W}\right)\end{array}$ & $\begin{array}{l}\text { BD Pres } \\
2019-2020\end{array}$ & $\begin{array}{l}\text { Historical sample } \\
\text { (BD Pres) }\end{array}$ \\
\hline $\mathrm{BC} 1$ & Bakers Creek at Gordon Road & Claiborne & $03 / 23 / 19$ & 31.89598 & 90.96961 & No & Yes (No) \\
\hline BP1 & Bayou Pierre at Old Red Star Dive & Lincoln & $03 / 22 / 19$ & 31.67598 & 90.52711 & No & Yes (No) \\
\hline BP2 & Bayou Pierre at Lott Smith Road & Lincoln & 03/22/19 & 31.68924 & 90.49264 & No & Yes (No) \\
\hline BP3 & Bayou Pierre at Cline Road & Copiah & $03 / 22 / 19$ & 31.75653 & 90.45947 & Yes (13) & No (No) \\
\hline BP4 & Bayou Pierre at Tyson Road & Copiah & $03 / 22 / 19$ & 31.78443 & 90.46580 & No & Yes (No) \\
\hline BP5 & Bayou Pierre at HWY 28 & Copiah & $07 / 11 / 19$ & 31.82843 & 90.48147 & No & No (No) \\
\hline BP6 & Bayou Pierre at Smyrna & Copiah & $05 / 24 / 19$ & 31.87004 & 90.49778 & Yes (18) & Yes (Yes) \\
\hline BP7 & Bayou Pierre at Turkey Creek confluence & Copiah & $08 / 21 / 19$ & 31.93317 & 90.52994 & No & Yes (Yes) \\
\hline BP8 & Bayou Pierre at bridge $2 / 3 \mathrm{mi}$ S Dentville & Copiah & $06 / 17 / 19$ & 31.95206 & 90.56438 & Yes (5) & Yes (Yes) \\
\hline BP9 & Bayou Pierre 2 km below Foster Creek & Copiah & 08/16/19 & 31.95707 & 90.64292 & No & No (No) \\
\hline BP10 & Bayou Pierre at HWY 18 upstream & Copiah & 06/17/19 & 32.00312 & 90.68973 & Yes (1) & Yes (No) \\
\hline BP11 & Bayou Pierre at White Oak Creek confluence & Copiah & $08 / 21 / 19$ & 32.02189 & 90.69181 & Yes (4) & Yes (No) \\
\hline BP12 & Bayou Pierre at Carslile Lane & Claiborne & $07 / 11 / 19$ & 32.00537 & 90.78409 & Yes (3) & Yes (Yes) \\
\hline BP13 & Bayou Pierre at Natchez Trace & Claiborne & $07 / 20 / 20$ & 32.01514 & 90.85259 & No & Yes (No) \\
\hline BP14 & Bayou Pierre at Whiskey Branch Creek & Claiborne & $07 / 24 / 20$ & 32.00558 & 90.89623 & No & Yes (No) \\
\hline BP15 & Bayou Pierre at Rapalje Creek & Claiborne & $07 / 24 / 20$ & 31.99834 & 90.92149 & No & No (No) \\
\hline BP16 & Bayou Pierre at HWY 18 downstream & Claiborne & $08 / 23 / 20$ & 31.98592 & 91.00749 & No & Yes (No) \\
\hline $\mathrm{CC} 1$ & Clarks Creek at SHWY 547 & Claiborne & $03 / 23 / 19$ & 31.85868 & 90.84678 & No & Yes (No) \\
\hline FC1 & Foster Creek at Barlow Road & Copiah & 05/23/19 & 31.83499 & 90.65750 & No & No (No) \\
\hline $\mathrm{FC} 2$ & Foster Creek at Smyrna Road & Copiah & 05/24/19 & 31.87593 & 90.62291 & Yes (4) & Yes (Yes) \\
\hline FC3 & Foster Creek $0.5 \mathrm{~km}$ above confluence & Copiah & 08/16/19 & 31.93563 & 90.62166 & No & Yes (Yes) \\
\hline JC1 & James Creek at Russum Westside Road & Claiborne & 03/23/19 & 31.91606 & 91.10839 & No & Yes (No) \\
\hline LBP01 & Little Bayou Pierre at SHWY 547 & Claiborne & 03/23/19 & 31.80452 & 90.73916 & No & Yes (No) \\
\hline LBP2 & Little Bayou Pierre at Barland Road & Claiborne & $06 / 18 / 19$ & 31.85007 & 90.74545 & No & Yes (No) \\
\hline LBP3 & Little Bayou Pierre at Pattison Road & Claiborne & $06 / 18 / 19$ & 31.90609 & 90.83539 & No & Yes (No) \\
\hline LBP4 & $\begin{array}{l}\text { Little Bayou Pierre, Little Bayou Pierre at } \\
\text { HWY } 65\end{array}$ & Claiborne & $09 / 21 / 19$ & 31.96524 & 90.98067 & No & Yes (No) \\
\hline LC1 & Long Creek at Rocky Fall Road & Copiah & 03/07/19 & 31.92749 & 90.47587 & No & Yes $(\mathrm{No})$ \\
\hline LC2 & Long Creek at Dentville Road & Copiah & $03 / 22 / 19$ & 31.92566 & 90.49378 & No & No (No) \\
\hline LT1 & Little Tallahalla Creek at Dry Grove Road & Hinds & 06/18/19 & 32.15610 & 90.44192 & No & No (No) \\
\hline LT2 & Little Tallahalla Creek at Chapel Hill Road & Hinds & 06/18/19 & 32.13324 & 90.54396 & No & No (No) \\
\hline LT3 & Little Tallahalla Creek at HW 27 & Hinds & 05/23/19 & 32.08173 & 90.59792 & Yes (6) & Yes (No) \\
\hline $\mathrm{TC} 1$ & Turkey Creek at Tanyard Road & Copiah & 03/07/19 & 31.97178 & 90.41954 & No & No (No) \\
\hline TC2 & Turkey Creek at Milsaps Road & Copiah & 03/07/19 & 31.95824 & 90.43762 & No & No (No) \\
\hline TC3 & Turkey Creek at Dentville Road & Copiah & $05 / 23 / 19$ & 31.94882 & 90.52165 & No & Yes (No) \\
\hline WC1 & Willis Creek at Tillman Road & Claiborne & 08/01/19 & 31.85704 & 90.91770 & No & No (No) \\
\hline WC2 & Willis Creek at HWY 547 & Claiborne & 08/01/19 & 31.91647 & 90.93034 & No & Yes (No) \\
\hline WdC1 & Widows Creek at Rodney Road & Claiborne & $09 / 21 / 19$ & 31.95557 & 91.06260 & No & Yes (No) \\
\hline WOC1 & White Oak Creek at Gallatin Road & Copiah & 08/01/19 & 32.02675 & 90.42458 & No & No (No) \\
\hline WOC2 & White Oak Creek at Bear Creek Road & Copiah & 05/23/19 & 32.04732 & 90.51361 & No & Yes (No) \\
\hline WOC3 & White Oak Creek at Low Water Bridge Road & Hinds & $08 / 02 / 19$ & 32.06027 & 90.58737 & Yes (4) & Yes (No) \\
\hline WOC4 & $\begin{array}{l}\text { White Oak Creek at Little Tallahalla Creek } \\
\text { confluence }\end{array}$ & Hinds & $08 / 02 / 19$ & 32.06206 & 90.61230 & Yes (5) & Yes (No) \\
\hline WOC5 & White Oak Creek at Bayou Pierre confluence & Copiah & 08/02/19 & 32.02857 & 90.68138 & Yes (2) & Yes (No) \\
\hline
\end{tabular}

ical sites of $N$. rubrum collection that do not appear to have full community data and/or information about collecting effort readily available. In particular, there are 56 lots containing 1050 individuals in the Tulane University collection taken primarily from lower White Oak Creek, the White Oak Creek confluence with Bayou Pierre, and Bayou Pierre below this confluence (Sites BP10, BP11, WOC5, and BP12 in Fig. 1). There are also over 350 individuals from mul- tiple lots in the Mississippi Museum of Natural Science and University of Southern Mississippi (USM) collections from Foster Creek (FC1, FC2, and FC3) and areas near the Turkey Creek-Bayou Pierre confluence (BP7, BP8, TC3, LC2) (Knight \& Ross 1994). Those locations without known standardized sampling effort are not part of our analyses. Other surveys of the basin were not included because sampling effort was not documented, sample count data 
are not available, or $N$. rubrum were released and no records of counts are known. However, given the large numbers of individuals taken from these areas, we discuss qualitative patterns of abundance through time below (see Discussion). All sampling was conducted in summer 2019, with the exception of the 4 lowest points on the Bayou Pierre which were not accessible due to flooding. These sites were sampled in summer 2020.

\subsection{Fish sampling}

At each site, we selected a 100-250 m reach (based on estimated wetted width) that included at least 1 swift water mesohabitat unit (i.e. riffle, run, or fast glide). Each reach was divided into 3 equal-length subsample plots. Fish were sampled by seining $(4 \mathrm{~m}$ $\times 1.5 \mathrm{~m}$ seine with $3 \mathrm{~mm}$ mesh) all available habitats with effort being in proportion to habitat availability. We employed kicksets within riffle habitats. With the exception of $N$. rubrum and crystal darters Crystallaria asprella, all fish were fixed in $10 \%$ buffered formalin, and later identified, transferred to $70 \%$ ethanol and deposited in the USM Ichthyological Collection. Prior to their release, individuals of C. asprella and $N$. rubrum were photographed with a reference ruler for later digital size measurement.

\subsection{Habitat sampling}

We measured habitat data using a point-transect method, with 3 transects per sample subplot (9 transects site ${ }^{-1}$ ) and points taken at roughly every meter of stream width. For each transect, we recorded the bankfull and wetted stream width to the nearest meter measured with a Nikon Aculon 6×20 6.0 $0^{\circ}$ digital range finder, visually classified bank stability (low, medium, high based on bank angle and evidence of recent erosion via exposed alluvial material) of both banks, and visually estimated percent canopy cover at the center of the transect. At each point on a transect, we recorded water depth $(\mathrm{cm})$, water velocity $\left(\mathrm{m} \mathrm{s}^{-1}\right.$, Hach Flowmate 2000), dominant substrate on a rank Wentworth scale $(1=$ clay/silt, $2=$ sand..., $6=$ bedrock), embeddedness (percentage visually estimated), and the presence of any available cover elements (woody structure, boulder/cobble). We calculated means and the coefficient of variation $(\mathrm{CV})$ for each of our reach-scale hydrogeomorphic variables (depth, current velocity, substrate size, wetted width, bankfull width, embeddedness, and woody structure).

\subsection{Analyses}

All analyses used contemporary and historical datasets with fish assemblage data at the same sites (except for the new sites added, see Section 2.1) and comparable methods and effort. We used traditional measures of diversity (Shannon's index, rarefied diversity) to describe patterns in historical and contemporary assemblages, and non-metric multidimensional scaling (NMDS) to summarize a Bray-Curtis similarity matrix of proportional abundance (McCune \& Grace 2002, Legendre \& Legendre 2012), and permutational MANOVA (Anderson 2001) to test for assemblage differences between historical and contemporary samples with and without $N$. rubrum. We plotted samples in NMDS space to qualitatively examine (1) similarity between historical and contemporary assemblages and (2) uniqueness of assemblage structure (historical and contemporary) associated with $N$. rubrum. For the first objective, we examined historical and contemporary patterns of abundance and occurrence of all taxa and qualitatively assessed if historical and contemporary samples overlapped in ordination space. For the second objective, we examined historical and contemporary assemblages associated with $N$. rubrum to assess if species associated with the presence of $N$. rubrum had changed over time. We tested for differences between historical and contemporary assemblages with and without $N$. rubrum with permutational MANOVA.

Network topology (link magnitude, Link-Mag) was extracted from stream attributes (watershed area and confluence-link) in the National Hydrography Dataset Plus (NHDPlus; www.horizon-systems.com/nhdplus/). Link-Mag is the summation of the number of first-order segments upstream of a given locality in a stream network (Fairchild et al. 1998). We extracted land use data for 2016 from the national land cover dataset (NLCD, https://www.mrlc.gov/data). That year was used because it was the closest to when the contemporary sites were sampled. NLCD data includes 20 classes of land use that we reclassified into 5 broad land-use variables: forested, urban, wetland, open water, and agricultural. We then estimated the relative area of each land-use type associated with each site's upstream watershed area. A principal component analysis (PCA) of the land-use data explained $45.5 \%$ of the variation (with forested land having the highest loading) and was used (hereinafter: LC1) in analyses. We estimated means and SDs of elevation change using the US Geological Survey (USGS) national elevation dataset (https:// 
www.nrcs.usda.gov/wps/portal/nrcs/detail/national/). We established three $200 \mathrm{~m}$ cross-sections at $1 \mathrm{~km}$ intervals (upstream, site, downstream) at each site, reasoning that unstable stream reaches should be characterized by a greater magnitude of elevation change or greater variation in elevation change within a reach. Elevation data were collected every $10 \mathrm{~m}$ along a cross-section and then used to calculate the average change in elevation (CE Avg) and the SD of elevation change (CE SD) for each site. These variables were included as covariates within our occupancy models. We used PCA to reduce the dimensionality of hydrogeomorphic variables, followed by a broken-stick model to determine how many axes to retain. We saved PC1, PC2, and PC3 scores (henceforth Hab1, Hab2, and Hab3) as descriptors of environmental variation at the reach scale.

We used single-species occupancy models to characterize reach-scale and landscape-scale environmental variation associated with the probability of occurrence ( $\Psi$ ) of N. rubrum (MacKenzie et al. 2002) using contemporary sites excluding Little Bayou Pierre. Because spatial replicates may not represent truly independent surveys and lead to the inflation of occupancy estimators (Kendall \& White 2009), we also developed spatial dependence models (Hines et al. 2010). Spatial dependence models allow the probability that a spatial segment may or may not be occupied based upon whether the previous segment was occupied $\left(\theta^{\prime}\right)$ or not $(\theta)$ (Hines et al. 2010) where parameters are modeled as a first-order Markov process. We used the logit link transformation to model $\Psi$ as a function of covariates. Due to our small sample size (n $=32$ ), detection $(p)$ was modeled as constant to reduce model complexity. Reach-scale habitat (Hab1, Hab2, and Hab3), elevational (CE Avg and CD SD), and landscape-scale (link magnitude, Link-Mag and LC1) variables were included as covariates to estimate $\Psi$. We used untransformed beta estimates to infer relationships (positive or negative) between covariates and occupancy. We standardized Link-Mag, CE Avg, and $\mathrm{CE}$ SD by subtracting the mean and dividing by twice the SD. Prior to modeling, we tested for the correlation between covariates. Any 2 covariates which had a Pearson correlation greater than the absolute value of 0.5 were not included in the same model. However, correlated variables were used as separate covariates for detection and occupancy within the same model. To assess the relative fit of our singlespecies occupancy models, we used the MacKenzieBailey goodness of fit test (MacKenzie \& Bailey 2004), in which overdispersion ( $\hat{c}$ ) is estimated by calculating the chi-squared goodness of fit statistic for a global model and then dividing it by the mean test statistic of 10000 bootstrap samples. To model $N$. rubrum abundance as a function of reach-scale and landscapescale environmental variation, we used zero-inflated Poisson regression models (R package 'glmmTMB') (Brooks et al. 2017). Zero-inflated regression models allow the user to account for overdispersion in the response variable by modeling zeros in a dataset as a function of a 2-state process. One of the 2 states, the zero state, may be defined as the probability of an event being so low that it cannot be readily differentiated from zero. The second state, the normal state, includes both zeros and continuous values falling within the interval $(0,1)$ (Liu \& Eugenio 2018). We modeled the zero state as a function of mean depth and current velocity. We included stream size as a random effect; stream size groupings were based on a site's LinkMag $($ small $=0$ to 30,30 to $100=$ medium, $>100=$ large; 10,10 , and 8 sites respectively).

We used Akaike's information criterion for small sample sizes $\left(\mathrm{AIC}_{\mathrm{c}}\right)$ to assess the quality of competing models (Anderson \& Burnham 2002). Models with small $\triangle \mathrm{AIC}_{\mathrm{c}}$ and large Akaike weights $\left(w_{\mathrm{i}}\right)$ indicate a more optimal balance of parsimony and fit (Anderson $\&$ Burnham 2002). We only interpreted models with $W_{\mathrm{i}}>0.10$. To prevent the inclusion of uninformative parameters, models which only differed in $\triangle \mathrm{AIC}_{\mathrm{c}}$ by 1-2 units from the best models and possessed similar log-likelihood values were removed (Anderson \& Burnham 2002). As an alternative to using a single best-supported model, we applied model averaging to quantify unconditional model average estimates of $\Psi$ and $p$, and associated standard errors (bounded between 0 and 1.0) for all occupancy and detection parameters within models with $w_{i}>0.001$.

To estimate the mean abundance of $N$. rubrum per site, we modeled abundance using the $N$-mixture model as described by (Royle 2004). Often, count data is used to estimate abundance or population size, ignoring the fundamental detection process which generated these data. When modeling abundance, it is presumed that the population under study is closed with respect to mortality, recruitment, and movement so that the counts may be construed as binomial random variables. This model makes 2 distributional assumptions:

$$
\begin{gathered}
n_{i j} \text { Binomial }\left(N_{i,} p\right) \\
N_{i} \text { Pois }\left(\lambda_{i}\right)
\end{gathered}
$$

where $n_{i j}$ is the number of $N$. rubrum counted at site $i$ in survey $j_{1} N_{i}$ is the number of $N$. rubrum present at site $i_{1} p$ is the probability of detection, and $\lambda_{i}$ is the conditional mean abundance of $N$. rubrum at site $i$. 
For our dataset, we assumed counts followed a Poisson (Pois) distribution and thus used the Poisson mixture. Due to time constraints, we substituted spatial replicates for temporal replicates to model $N_{i}$. While we recognize that our observed data do not represent true temporally, replicated counts, estimates of abundance are much preferred by state and federal agencies so that they can more effectively manage federally threatened species such as $N$. rubrum. We did not model $N_{i}$ as a function of our environmental covariates; we only constructed a null model to obtain an estimate of $N_{i}$. All hierarchical models were constructed using the package 'unmarked' in R (version 0.13-1) (Fiske \& Chandler 2011).

\section{RESULTS}

\subsection{Fish assemblages}

The 42 contemporary samples contained 20855 individuals representing 71 species. The most abundant species were Cyprinella venusta (mean of 261 site $^{-1}$, collected at 33 sites), Notropis volucellus (100.4 site $^{-1}$ at 20 sites), $N$. atherinoides (81.4 site $^{-1}$ at 15 sites), $N$. longirostris (34.8 site $^{-1}$ at 34 sites), and Percina vigil (41.2 site $^{-1}$ at 25 sites). The most commonly occurring species were Fundulus olivaceus and N. longirostris (both 34 sites), and C. venusta, C. camura, and Lepomis megalotis (each 33 sites). The 51 historical samples contained 11243 individuals representing 63 species. Notable changes in species rank abundance between historical and contemporary include increases in $N$. atherinoides (increase in rank from 38 to 3 ), N. volucellus (increase in rank from 25 to 2), and $P$. vigil (increase from 14 to 5), and declines in C. lutrensis (decrease in rank from 2 to 13) and Etheostoma lynceum (decrease from 4 to 17). All species present in 1 of the 2 datasets and absent from the other were rare, occurring in 4 or fewer samples. Measures of diversity were similar between contemporary (Shannon's index: $1.8 \pm 0.08 \mathrm{SE}$, rarefied diversity: $11.3 \pm$ $0.48 \mathrm{SE}$ ) and historical (Shannon's index: $1.8 \pm 0.05$ $\mathrm{SE}$, rarefied diversity: $11.1 \pm 0.32 \mathrm{SE}$ ) collections.

\subsection{Nothonotus rubrum occurrence and abundance}

We collected $65 N$. rubrum at 11 sites (26\% of sites sampled), a similar rate of capture as in the historical samples (8 sites, 27.5\%). Four of the 11 sites were localities where $N$. rubrum were sampled in histori-

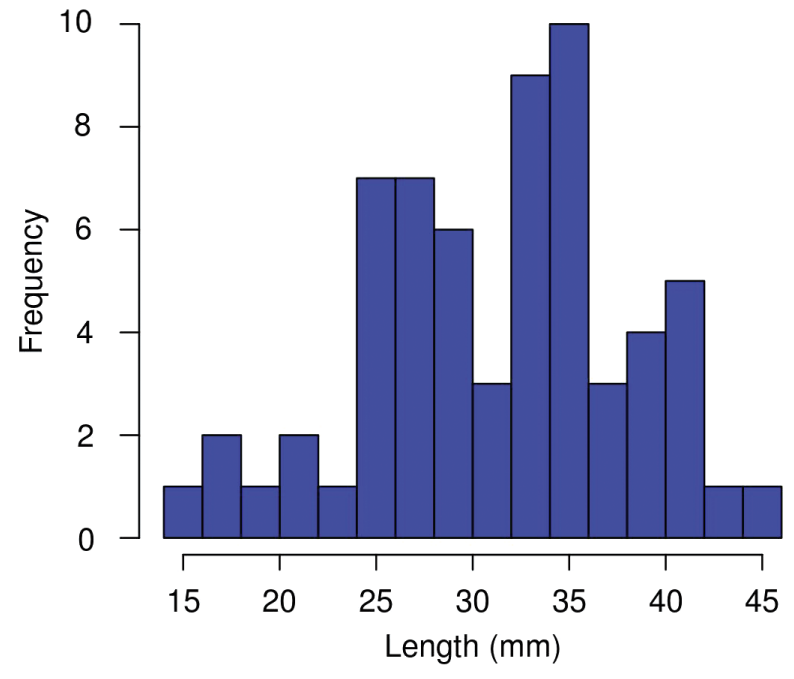

Fig. 2. Size distribution (standard length) of Nothonotus rubrum sampled in 2019

cal collections (green stars, Fig. 1). Seven of the sites with $N$. rubrum did not have any occurrences in historical data (orange stars), while 2 sites with $N$. rubrum historically did not have any in our collections (red diamonds). The mean (5.9 contemporary, 11.6 historical) and maximum (18 contemporary, 48 historical) number of $N$. rubrum captured at sites where present was similar between contemporary and historical samples. Note that in the historical dataset, sites with $N$. rubrum were often sampled multiple times, most likely to provide adequate sample size for life history, genetic, or diet study objectives. Some other sites are known to contain $N$. rubrum, but they were absent in collections from those sites in the historical dataset (see Section 2.1). There were 2 further localities sampled opportunistically while hiking to other sites. These sites contained habitat that appeared ideal, and both sites contained $N$. rubrum. We did not include data from these 2 occurrences in analyses because the same standard sampling protocol was not followed. These additional sites are also not represented on Fig. 1. Two of the $65 N$. rubrum were taken as vouchers, while the remaining 63 were photographed to obtain standard length and estimate mass. The mean size of $N$. rubrum collected was $31.3 \mathrm{~mm}$ (6.6 SD), with a range from 15.1 to $44.9 \mathrm{~mm}$ (Fig. 2).

\subsection{Synthesis of reach-scale environmental variation}

The PCA of our hydrogeomorphic variables revealed physical habitat gradients associated with stream 
slope and stream size. The strongest loadings on Hab1 ( $27.2 \%$ variance explained, Table 2$)$ were substrate size $(-1.13)$, embeddedness (1.03), and the $\mathrm{CV}$ of embeddedness (-1.02). Important loadings on Hab2 (17.1\% variance explained, Table 2$)$ included wetted width (-0.82), the bankfull width $(-0.88)$, and canopy cover $(-0.82)$. Finally, variables with the greatest loadings on Hab3 (12.2\% variance ex plained, Table 2) included $C V$ of wetted width and CV of bankfull width. Thus, Hab1 represented a depth and substrate gradient; sites with negative scores along Hab1 were characterized by more coarse sediments and shallower depths. Hab2 represented a stream size gradient; sites with positive scores along Hab2 were characterized by narrower active channel widths and a greater percentage of canopy cover. Hab3 represented an erosion gradient; sites with positive scores along Hab3 were characterized by greater variability in active channel and bankfull widths.

\subsection{Hierarchical modeling of $\mathbf{N}$. rubrum occurrence and abundance}

$N$. rubrum were detected at 11 of the 32 sampled sites analyzed, yielding a naïve occupancy estimate of 0.34 . When modeling detection as constant, we obtained an unconditional estimate for $p$ of $0.33 \pm$ 0.11 . Preliminary analyses indicated that the singleseason null model was better supported $\left(w_{i}=0.92\right)$ than the spatial dependence null model, suggesting that detections were not spatially autocorrelated, jus-

Table 2. Variables and loadings for the first 6 axes from the principal component analysis. Percent variance explained is included for each axis. CV: coefficient of variation

\begin{tabular}{|lrrr|}
\hline Variable & PC1 & PC2 & PC3 \\
& $27.2 \%$ & $17.1 \%$ & $12.2 \%$ \\
\hline Depth & 0.788 & 0.252 & -0.305 \\
Current velocity & -0.361 & 0.823 & 0.528 \\
Substrate size & -1.128 & 0.024 & -0.114 \\
\% Embeddedness & 1.028 & -0.024 & -0.114 \\
\% Woody structure & 0.848 & -0.245 & -0.416 \\
\% Canopy cover & -0.177 & -0.816 & -0.374 \\
Wetted width & 0.207 & 0.818 & -0.374 \\
Bankfull width & 0.102 & 0.879 & 0.378 \\
CV of depth & -0.019 & -0.438 & 0.336 \\
CV of current velocity & -0.310 & -0.452 & -0.318 \\
CV of substrate size & -0.722 & -0.068 & -0.264 \\
CV of \% embeddedness & -1.018 & 0.107 & -0.287 \\
CV of \% woody structure & 0.228 & 0.433 & -0.298 \\
CV of \% canopy cover & 0.004 & 0.435 & -0.140 \\
CV of wetted width & 0.041 & -0.317 & 0.835 \\
CV of bankfull width & -0.045 & -0.001 & 0.851 \\
\hline
\end{tabular}

tifying the use of spatial replicates for $p$. Our global model indicated no evidence of a lack of model fit $(p=0.56, \hat{\mathrm{c}}=0.82)$. Occupancy of $N$. rubrum was best modeled by Link-Mag and Hab2 (Table 3), with a positive relationship to Link-Mag (beta estimate, $3.07 \pm 1.87$, Fig. 3) and negative relationship to Hab2 (beta estimate, $-0.73 \pm 0.79$, Fig. 3). Our null model of abundance estimated the $N_{i}$ of $N$. rubrum at $7.36 \pm$ 3.83 individuals site $^{-1}$. N. rubrum counts were best modeled as a function of the variation in elevation change at the kilometer scale (Table 4 ) with a significant, negative relationship (beta estimate $=-0.60$; $\mathrm{p}<0.001$ ) between CE SD and $N$. rubrum counts.

\subsection{Fish assemblages}

Historical and contemporary fish assemblages without $N$. rubrum were generally concordant and overlapped broadly in ordination space (light and dark gray polygons in Fig. 4), while historical and contemporary assemblage structure at sites with $N$. rubrum diverged in ordination space (blue and green polygons in Fig. 4). Non-parametric MANOVA indicated significant differences between historical and contemporary assemblages that were much more pronounced (more variance explained by time variable) in samples with $N$. rubrum $\left(F_{1,32}=7.2, \mathrm{R}^{2}=0.19\right.$, $\mathrm{p}<0.001)$ compared to samples without $N$. rubrum $\left(F_{1,32}=3.2, \mathrm{R}^{2}=0.05, \mathrm{p}<0.003\right)$. The 2 species most

Table 3. Single-species occupancy models and interceptonly models for occurrence of Bayou darters sampled in the Bayou Pierre River system. K: number of parameters, $\mathrm{AIC}_{\mathrm{C}}$ : Akaike's information criterion for small sample sizes; $W_{i}$ : model weights; $p$ : probability of detection; $\Psi$ : probability of occurrence; Link-Mag: link magnitude; Hab1, Hab2, and Hab3: reach-scale habitat variables; CE SD: standard deviation of elevation change; CE Avg: average change in elevation. Intercept-only models are designated by periods in place of covariates. Models with parameters $\theta$ and $\theta^{\prime}$ indicate spatial-dependence models with the probability that a spatial segment may or may not be occupied based on whether the previous segment was occupied $\left(\theta^{\prime}\right)$ or not $(\theta)$

\begin{tabular}{|lcccc|}
\hline Model & $K$ & $\mathrm{AIC}_{\mathrm{c}}$ & $\Delta \mathrm{AIC}_{\mathrm{c}}$ & $w_{i}$ \\
\hline$p(),. \Psi$ (Link-Mag) & 3 & 80.41 & 0 & 0.70 \\
$p(.) \Psi$ (Hab2) & 3 & 82.47 & 2.06 & 0.25 \\
$p(),. \Psi()$. & 2 & 88.16 & 7.75 & 0.01 \\
$p(),. \Psi$ (Hab3) & 3 & 88.98 & 8.57 & 0.01 \\
$p(),. \Psi$ (Land use) & 3 & 89.17 & 8.76 & 0 \\
$p(),. \Psi$ (CE SD) & 3 & 89.54 & 9.13 & 0 \\
$p(),. \Psi$ (Hab1) & 3 & 89.83 & 9.42 & 0 \\
Global & 9 & 90.30 & 9.89 & 0 \\
$p(),. \Psi$ (CE Avg) & 3 & 90.65 & 10.24 & 0 \\
$p(),. \Psi(),. \theta(.) \theta^{\prime}()$. & 5 & 95.05 & 15.28 & 0 \\
\hline
\end{tabular}



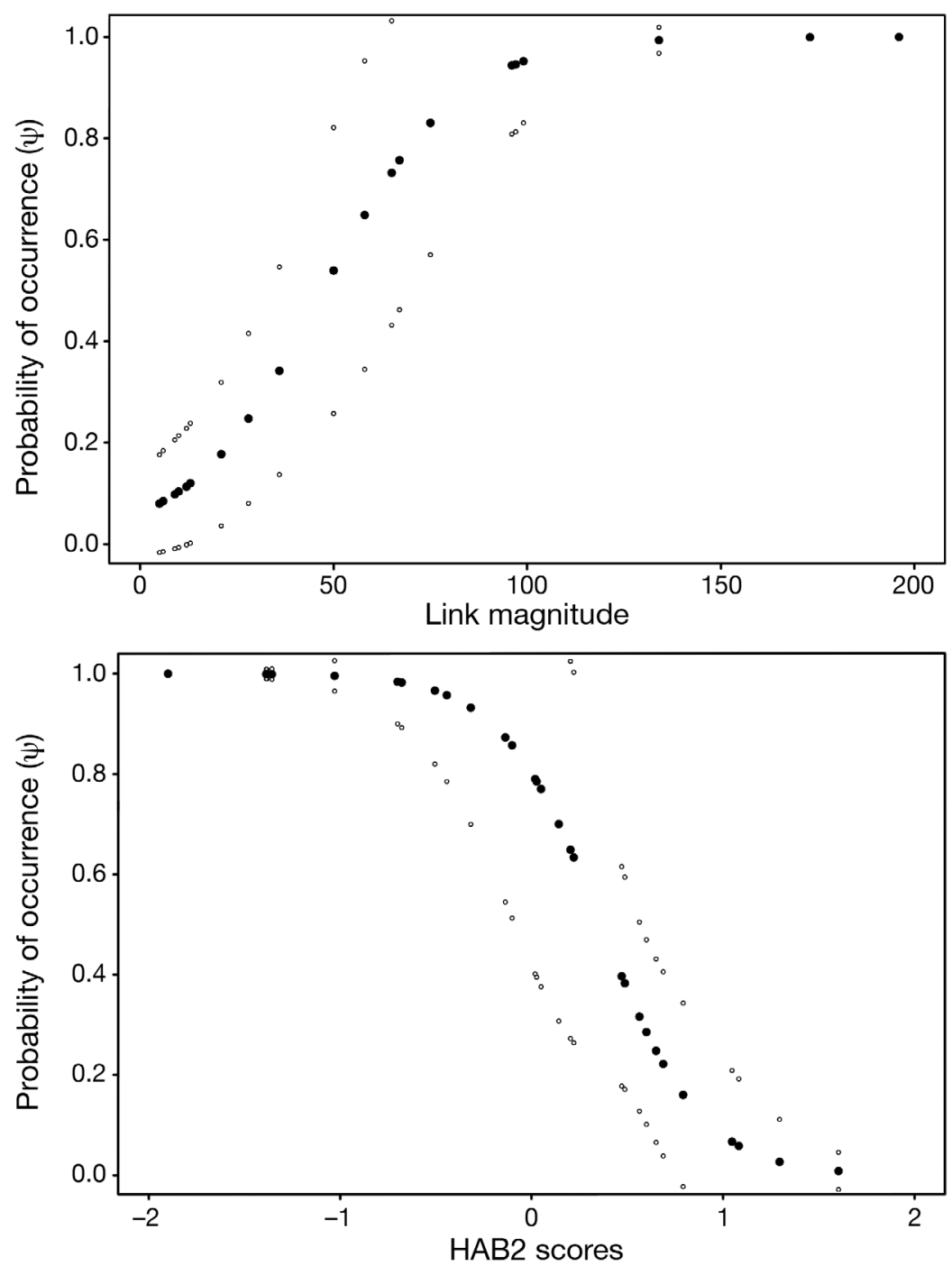

Fig. 3. Predicted values of Bayou darter occupancy plotted against link magnitude (upper panel) and Hab2 scores (lower panel) for the 28 surveyed sites. Black circles: predicted values; white circles: $95 \%$ confidence limits

Table 4. Zero-inflated Poisson mixed effects models of Bayou darter counts sampled in the Bayou Pierre River system. $K$ : number of parameters; $\mathrm{AIC}_{\mathrm{c}}$ : Akaike's information criterion for small sample sizes; $w_{i}$ : model weights; CE SD: standard deviation of elevation change; CE Avg: average change in elevation; Hab1, Hab2, and Hab3: reach-scale habitat variables

\begin{tabular}{|lcccc|}
\hline Model & $K$ & $\mathrm{AIC}_{\mathrm{c}}$ & $\Delta \mathrm{AIC}_{\mathrm{c}}$ & $W_{i}$ \\
\hline Abundance $\sim$ CE SD + 1 I Stream size & 3 & 80.41 & 0 & 0.70 \\
Abundance $\sim$ Land use + 1 Stream size & 3 & 82.47 & 5.08 & 0.05 \\
Abundance $~ 1$ + 1I Stream size & 2 & 88.16 & 9.9 & 0.01 \\
Abundance $\sim$ CE Avg + 1I Stream size & 3 & 88.98 & 11.2 & 0 \\
Abundance $\sim$ Hab1 + 1I Stream size & 3 & 89.17 & 11.3 & 0 \\
Abundance $\sim$ Hab2 + 1I Stream size & 3 & 89.54 & 12.4 & 0 \\
Global & 3 & 89.83 & 12.5 & 0 \\
Abundance $\sim$ Hab3 + 1I Stream size & 9 & 90.30 & 13.1 & 0 \\
\hline
\end{tabular}

characteristic of these changes were $E$. lynceum (present in all 14 historical samples with $N$. rubrum at a mean abundance of 37.0 , present in all contemporary samples with $N$. rubrum, but a mean abundance of 9.1), and $C$. venusta (present in all 14 historical samples with $N$. rubrum at a mean abundance of 53.5, present in all contemporary samples with $N$. rubrum, but a mean abundance of 284.3). P. vigil also increased in abundance and is commonly found with $N$. rubrum. Historically, P. vigil occurred at 12 of 14 sites with $N$. rubrum at a mean abundance of 3.6. In contemporary samples, $P$. vigil was found in all samples with $N$. rubrum at a mean abundance of 60.5 (range among samples of 2-170, and 3 samples having $>100$ ). Mean abundance of $P$. vigil in contemporary samples without $N$. rubrum was just 11.8.

\section{DISCUSSION}

We captured Nothonotus rubrum at a similar proportion of contemporary samples $(28 \%)$, and in similar abundance (6-7 individuals sample $\left.{ }^{-1}\right)$ in comparison to the historical samples from 1987-1992. While current rates of occurrence and abundance are similar, the trends appear to show flat or declining abundance and continued movement up in the watershed. We chose these historical samples for direct comparison after reviewing field notes and, when possible, discussion with the researchers who conducted those early surveys. All evidence suggested these samples were from comparable sampling of fish assemblages that did not target $N$. rubrum (i.e. no bias towards riffle habitat). There are many other historical records of $N$. rubrum that do not appear to be from comparable sampling efforts (or proper documentation is lacking), complicating assessment of long-term trends in abundance. However, even with differences in sampling approaches, there are some striking 


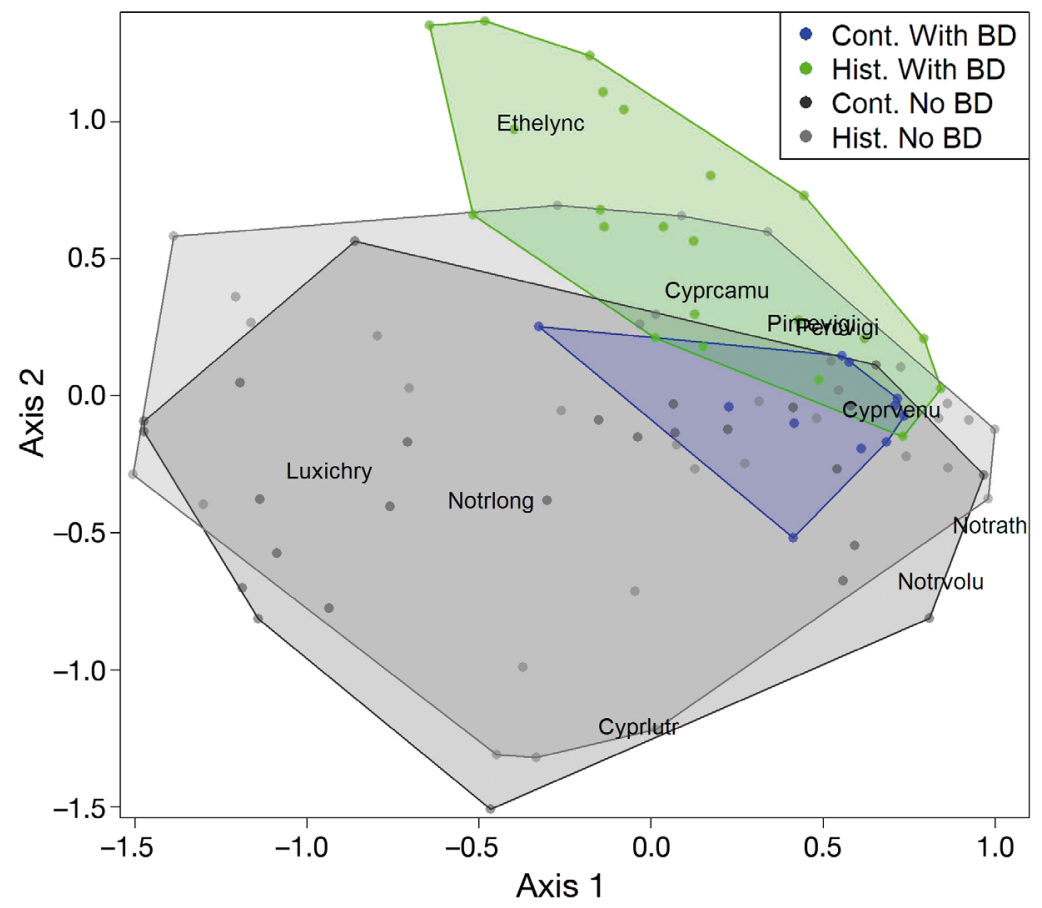

Fig. 4. Nonmetric multidimensional scaling analysis $(K=2$, Bray-Curtis similarity) of historical and contemporary relative abundances. Minimum convex polygons surround samples parsed into 4 groups: contemporary (Cont.) and historical (Hist.) samples with and without Bayou darter (BD). Weighted average scores for the 10 most abundant species are plotted (Cyprcamu: Cyprinella camura; Cyprlutr: C. lutrensis; Cyprvenu: C. venusta; Ethelync: Etheostoma lynceum; Luxichry: Luxilus chrosocephalus; Notrath: Notropis atherinoides; Notrlong: N. longirostris; Notrvolu: N. volucellus; Percvigi: Percina vigil; Pimvigi: Pimephales vigilax

changes in where $N$. rubrum occurrs in high abundance. The largest number of vouchered N. rubrum specimens is found in the Tulane University collection, with 1050 individuals from 56 lots. The majority of these collections (including 7 lots with $>50$ individuals, 2 lots $>100$ ) were taken before 1980 from the White Oak Creek confluence downstream of Carlisle. During this same period, there were fewer than 70 individuals vouchered at sites above the White Oak Creek Confluence (Site BP11 in Fig. 1). In contrast, N. rubrum samples in the 1980s and 1990s focused further upstream with nearly 600 individuals vouchered from upper Bayou Pierre, the Turkey Creek confluence, and Foster Creek. During that same period, there were just 29 individuals captured from the White Oak Creek confluence and below. In our sampling, we captured 10 individuals from the White Oak Creek confluence and below, and 55 from sites higher in the watershed. Some of our most productive sites (Bayou Pierre at Cline Road, sites at the confluence of White Oak Creek and Little Tallahalla Creek) were sites higher in the watershed with lower historical abundance.
Much of the early research was aimed at describing the species, and its ecology and life history in order to properly manage it. Those objectives require larger sample sizes, and efforts to document abundance were somewhat secondary. Thus, researchers at that time were targeting areas with the highest local abundance. The areas where $N$. rubrum appear to be in highest abundance shifted upstream from 1960-1970 to 1980-1990. It seems unlikely that there are any areas with abundances as high as observed in the 1960 s or 1970s. Given our observed and estimated abundances, even if sampling targeted riffle habitat at the highest abundance sites, it seems inconceivable that one could capture $>100$ individuals at a site today. More troubling, our estimate does not distinguish among age-classes; rather it was quantified using counts of both juveniles and adults at a site. Knight \& Ross (1994) reported densities of 2.5 to 3.4 individuals $\mathrm{m}^{-2}$, presumably in ideal riffle habitat. Today, these densities from the 1980-1990 period seem like a bestcase scenario and certainly not typical. The long-term trends for this species are troubling, as the distribution has moved up the watershed, while abundance seems to be declining. Continued push of this species into headwaters would likely result in smaller and more isolated populations, complicating conservation efforts. It should be noted that our assessment here is based on limited temporal sampling (2019-2020) and could be biased from population stochasticity. While we do not feel this is the case, given that observed size distributions (our Fig. 2) were similar to those previously published (Slack et al. 2004), more frequent sampling of these populations is warranted. Our findings suggest that $N$. rubrum was generally sampled from reaches typified by stable active channels. The magnitude and variability in elevation change within stream reaches where we sampled $80 \%$ (52 individuals, 8 sites) of $N$. rubrum individuals was reduced $(0.53 \pm 0.09)$ in relation to all other sampled localities $(0.63 \pm 0.21)$. Following Schumm et al. (1984), these sites occurred in geomorphic zones that were historically classified as either stage II or III (Ross et al. 2001). Contemporary habitat data suggests that $N$. rubrum occupied sites that were characterized by moderately sloping banks, defined berms with vegetation, stable point bars, and 
consolidated riffle habitats typified by cobble and gravel substrates. Given the qualitative approach used in Ross et al. (2001), e.g. visual assessment of aerial photographs, to classify geomorphic zones, it is difficult to ascertain whether geomorphic variability at these localities has resulted in substantial habitat change at the reach scale over the last 26 yr. A more quantitative approach similar to the method used in the present study (i.e. standardized cross-sections to assess geomorphic variation) should be used in future studies to assess the degree of habitat change at sites typified by Bayou darter presence.

The shifting $N$. rubrum distribution is consistent with geomorphological changes in the Bayou Pierre watershed. Ross et al. (2001) documented erosional waves rapidly moving up through the watershed. These erosional waves resulted in the loss of riffle habitat, due primarily to downstream transport of finer sediments, and channel modifications. At the same time, there was creation of some new riffle habitat above knickpoints, leading to the hypothesis that $N$. rubrum populations may move with erosional waves. The system has been quite dynamic, with knickpoints moving upstream at rates close to $750 \mathrm{~m}$ $\mathrm{yr}^{-1}$. However, conserving $N$. rubrum by having populations 'ride' these waves up the watershed is not sustainable, as there is only so far to go. N. rubrum are likely responding to substrate changes, but they are adapted to large creek and small river habitat in the middle/lower portions of the watershed. The highabundance habitats where they were found historically have cumulative watershed areas of $\sim 1500 \mathrm{~km}^{2}$ (near White Oak Creek Confluence), compared to most sites where we sampled $>5$ individuals that have a cumulative watershed area $<500 \mathrm{~km}^{2}$. Such inferences are supported by our occupancy modeling results, which make it clear that the microhabitat preferences of this darter are most commonly found in large streams (Fig. 3). While these smaller creeks may contain the most suitable substrate, there are a variety of other differences in those habitats for which $N$. rubrum may not be adapted, putting populations at risk.

Current and historical assemblages were generally quite similar, with a few notable exceptions. First, historical and current assemblages at sites without $N$. rubrum overlapped broadly, indicating little change. The subset of sites that contained $N$. rubrum show more change with less overlap between historical and current samples (Fig. 4). Most of the sites with $N$. rubrum are in the middle and upper portions of the watershed where the most active erosion is occurring. Thus, it appears there may be more fish assemblage changes at sites that are undergoing more recent physical change. Assemblage changes in darters include a reduction in the numbers of Etheostoma lynceum, which are often found in shallower habitat with larger substrate, and increases in Percina vigil and Crystallaria asprella. Both P. vigil and C. asprella are more abundant in large swift streams with sand, gravel, or hard packed clay substrate (Ross 2000, Boschung \& Mayden 2004). In cyprinids, there were fewer red shiner Cyprinella lutrensis, and more Cyprinella venusta and Notropis volucellus in contemporary samples. In the historical data, C. lutrensis was often numerically dominant at fewer sites (in the historical data, it was second most abundant while only occurring in $45 \%$ of samples). The contemporary samples only contained 1 site dominated by C. lutrensis, James Creek (JC1), which is the lowest tributary in the system and $<10 \mathrm{~km}$ from Mississippi River.

Current management recommendations for N. rubrum include action to reduce ongoing geomorphic change in the system. It is not entirely clear how successful any such efforts have been, and a thorough analysis of how knickpoints continue to move through the system is needed. Increased frequency and resolution of remote sensing data, in combination with historical data and analyses (Ross et al. 2001), should provide a clearer picture of how this system continues to change physically and biologically. There are occasional reports of $N$. rubrum seen downstream, which may be a result of the fairly mobile life history (Slack et al. 2004, 2010). As noted above, it has been over 30 yr since Bayou darters were sampled in large numbers at and below the confluence with White Oak Creek. Given the overall patterns in abundance, additional and more frequent sampling would be valuable in assessing whether lower numbers observed in 2019 are part of a continuing trend or an anomaly. The large abundances seen in lower portions of the basin in the 1960s and 1970s sampling needs to be better understood. A review of pertinent field notes, and study of the demographic patterns in those samples (e.g. size distributions to infer age), would be beneficial in putting those numbers in context. Our contemporary data represents a single snapshot that may not fully represent the status of these populations. Regular surveys are needed (and planned) to assess the longer-term stability of these populations.

Acknowledgements. Funding was provided by the US Fish and Wildlife Service. We thank S. Ross, T. Slack, and M. Wagner for assistance and insights regarding vouchered collections, and historical field notes and efforts. We thank M. Aiken, S. Barrett, A. Coomes, M. Dunning, A. Grieshober, and R. Spiers for assistance with field collections. 


\section{LITERATURE CITED}

Anderson MJ (2001) A new method for non-parametric multivariate analysis of variance. Austral Ecol 26:32-46

Anderson DR, Burnham KP (2002) Avoiding pitfalls when using information-theoretic methods. J Wildl Manag 66: 912-918

Boschung HT, Mayden RL (2004) Fishes of Alabama. Smithsonian Books, Washington, DC

Brooks ME, Kristensen K, van Benthem KJ, Magnusson A and others (2017) GlmmTMB balances speed and flexibility among packages for zero-inflated generalized linear mixed modeling. R J 9:378-400

Cross FB (1967) Handbook of fishes of Kansas. Museum of Natural History, University of Kansas, Lawrence, KS

Deacon JE, Kobetich G, Williams JD, Contreras S (1979) Fishes of North America endangered, threatened, or of special concern: 1979. Fisheries (Bethesda, Md) 4:29-44 www.nativefishlab.net/library/textpdf/12741.pdf

Etnier DA, Starnes WC (1993) The fishes of Tennessee. University of Tennessee Press, Knoxville, TN

Fairchild GW, Horwitz RJ, Nieman DA, Boyer MR (1998) Spatial variation and historical change in fish communities of the Schuylkill River drainage, southeast Pennsylvania. Am Midl Nat 139:282-295

Fiske I, Chandler R (2011) unmarked: an R package for fitting hierarchical models of wildlife occurrence and abundance. J Stat Softw 43:10

Hines JE, Nichols JD, Royle JA, MacKenzie DI, Gopalaswamy AM, Kumar NS, Karanth KU (2010) Tigers on trails: occupancy modeling for cluster sampling. Ecol Appl 20:1456-1466

Jelks HL, Walsh SJ, Burkhead NM, Contreras-Balderas S and others (2008) Conservation status of imperiled North American freshwater and diadromous fishes. Fisheries (Bethesda, Md) 33:372-407

Kendall WL, White GC (2009) A cautionary note on substituting spatial subunits for repeated temporal sampling in studies of site occupancy. J Appl Ecol 46:1182-1188

Knight JG, Ross ST (1992) Reproduction, age and growth of the Bayou darter Etheostoma rubrum (Pisces, Percidae): an endemic of Bayou Pierre. Am Midl Nat 127:91-105

Knight JG, Ross ST (1994) Feeding habits of the Bayou darter. Trans Am Fish Soc 123:794-802

Kuhajda BR, George AL, Williams JD (2009) The desperate dozen: Southeastern freshwater fishes on the brink. Southeast Fishes Counc Proc 51:10-25

Legendre P, Legendre L (2012) Numerical ecology, 3rd edn. Elsevier, Amsterdam

Lister AM (2011) Natural history collections as sources of long-term datasets. Trends Ecol Evol 26:153-154

Liu F, Eugenio EC (2018) A review and comparison of Bayesian and likelihood-based inferences in beta regression and zero-or-one-inflated beta regression. Stat Methods Med Res 27:1024-1044

MacKenzie DI, Bailey LL (2004) Assessing the fit of siteoccupancy models. J Agric Biol Environ Stat 9:300-318

MacKenzie DI, Nichols JD, Lachman GB, Droege S, Royle JA, Langtimm CA (2002) Estimating site occupancy rates when detection probabilities are less than one. Ecology 83:2248-2255

Matthews W (1978) Fishes of Bayou Pierre, SW Mississippi. Unpublished MS thesis, Northeast Louisiana University, Monroe, LA

Editorial responsibility: Eduardo Martins,

Vancouver, British Columbia, Canada

Reviewed by: 3 anonymous referees
Matthews WJ (2015) Basic biology, good field notes, and synthesizing across your career. Copeia 103:495-501

McCune B, Grace JB (2002) Analysis of ecological communities. MJM Software, Glendale Beach, OR

Quinn TP (2018) The behavior and ecology of Pacific salmon and trout. University of Washington Press, Seattle, WA

* Raney E, Suttkus R (1966) Etheostoma rubrum, a new percid fish of the subgenus Nothonotus from Bayou Pierre, Mississippi. Tulane Stud Zool 13:95-102

Robison HW, Buchanan TM (2020) Fishes of Arkansas. University of Arkansas Press, Fayetteville, AR

Ross ST (2000) Inland fishes of Mississippi. University Press of Mississippi, Oxford, MS

Ross ST, Wilkins SD (1993) Reproductive behavior and larval characteristics of the threatened Bayou darter (Etheostoma rubrum) in Mississippi. Copeia 1993:1127-1132

* Ross ST, Knight JG, Wilkins SD (1992) Distribution and microhabitat dynamics of the threatened Bayou darter, Etheostoma rubrum. Copeia 1992:658-671

Ross ST, Knight JG, Wilkins SD (1990) Longitudinal occurrence of the bayou darter(Percidae: Etheostoma rubrum) in Bayou Pierre - a response to stream order or habitat availability? Pol Arch Hydrobiol 38:221-233

* Ross ST, O'Connell M, Patrick DM, Latorre CA, Slack WT, Knight JG, Wilkins SD (2001) Stream erosion and densities of Etheostoma rubrum (Percidae) and associated riffle-inhabiting fishes: biotic stability in a variable habitat. Copeia 2001:916-927

Royle JA (2004) N-mixture models for estimating population size from spatially replicated counts. Biometrics 60: 108-115

Schaefer JF (2011) Survey of Little Bayou Pierre for Etheostoma rubrum populations. Final report. US Fish and Wildlife Service, Ecological Services Field Office, Jackson, MS

Schumm SA, Harvey MD, Watson CC (1984) Incised channels: morphology, dynamics, and control. Water Resources Publications, Littleton, $\mathrm{CO}$

* Slack WT, Ross ST, Ewing JA (2004) Ecology and population structure of the Bayou darter, Etheostoma rubrum: disjunct riffle habitats and downstream transport of larvae. Environ Biol Fishes 71:151-164

Slack WT, Summers JA, Rooney AP, Taylor CM (2010) Conservation genetics of the threatened Bayou darter (Percidae: Etheostoma rubrum) in the Bayou Pierre system of southwestern Mississippi. Copeia 2010:176-180

Suttkus RD, Clemmer GH (1977) A status report on the Bayou darter, Etheostoma rubrum, and the Bayou Pierre system. Southeast Fishes Counc Proc 1:1-2

*Taylor AT, Long JM, Tringali MD, Barthel BL (2019) Conservation of black bass diversity: an emerging management paradigm. Fisheries (Bethesda, Md) 44:20-36

Teels B (1976) The ecology of endangered fishes in Bayou Pierre. In: Proc Miss Water Resour Conf. Water Resources Research Institute, Mississippi State University, Starkville, MS, p 73-78

Tipton JA, Bart HL, Piller KR (2004) Geomorphic disturbance and its impact on darter (Teleostomi: Percidae) distribution and abundance in the Pearl River drainage, Mississippi. Hydrobiologia 527:49-61

Williams JE, Johnson JE, Hendrickson DA, ContrerasBalderas S and others (1989) Fishes of North America endangered, threatened, or of special concern: 1989. Fisheries (Bethesda, Md) 14:2-20

Submitted: May 27, 2020

Accepted: November 19, 2020

Proofs received from author(s): February 20, 2021 